\title{
Predictors of cigarette use amongst Pacific youth in New Zealand
}

Tasileta Teevale ${ }^{1,3^{*}}$, Simon Denny ${ }^{2}$, Vili Nosa ${ }^{3}$ and Janie Sheridan ${ }^{4}$

\begin{abstract}
Background: Despite progressive population health policies to reduce tobacco harm, smoking prevalence continues to be inequitable amongst key ethnic groups in New Zealand. The purpose of this study is to describe the predictors of cigarette use amongst Pacific youth in New Zealand.

Methods: Data were collected as part of Youth'07, a nationally representative survey of the health and well-being of New Zealand adolescents. The study sample comprised 5471 students and this includes 1,178 were Pacific youth.

Results: The smoking prevalence rate for Pacific youth was twice that of New Zealand European youth. Pacific girls and older age groups, ages 16-17, smoked more than Pacific boys and younger adolescents. Pacific youth from higher and mid-deprivation neighbourhoods smoked at twice the rate of youth from low deprivation areas. Local neighbourhood stores (dairies) were the most used location for purchasing cigarettes, and only $12.7 \%$ of underaged adolescents were asked "most of the time" for age identification. Pacific adolescent smoking was associated with parental smoking, peer-group smoking and binge drinking. Parents not knowing the whereabouts of adolescents during after-school hours and night-times were also associated with adolescent smoking. A majority of Pacific adolescent smokers (70.2\%) had tried to quit smoking.

Conclusion: The strategies for addressing ethically the issue of equal health for all is to allocate increased public health investments towards targeted quit-smoking treatment programmes for Pacific youth in New Zealand. Further qualitative studies with Pacific youth to inform the development of culturally-appropriate youth-focused quitsubstance interventions is recommended.
\end{abstract}

\section{Background}

Tobacco is the second major cause of death in the world and is currently responsible for the death of one in ten adults' worldwide (about 5 million deaths per year) [1]. World Health Organization (WHO) estimates that, if current smoking patterns continue, it will cause some 10 million deaths every year by 2020 , while half the people that smoke today will eventually be killed by tobacco [1].

In the New Zealand context, despite decades of comprehensive tobacco control efforts, tobacco use remains the largest preventable cause of death and disease and in line with other countries, there are large differences in the smoking prevalence between major ethnic groups $[1,2]$. Although New Zealand has achieved an overall

\footnotetext{
* Correspondence: t.teevale@auckland.ac.nz

'School of Population Health, University of Auckland, Auckland, New Zealand ${ }^{3}$ Pacific Health, School of Population Health, University of Auckland, Private bag 92019, Auckland 1142, New Zealand

Full list of author information is available at the end of the article
}

reduction in tobacco use, the gap in smoking prevalence between lower and higher SES groups and between different ethnic groups has increased [3]. Compared to European New Zealanders (smoking prevalence for men $16 \%$; women 17\%), Maori (the indigenous people of New Zealand, smoking prevalence for men 38\%; women 44\%) and Pacific Peoples (diaspora from South Pacific island nations of Samoa, Cook Islands, Tonga, Niue, Tokelau, Fiji and other smaller islands; smoking prevalence for men $28 \%$; women $25 \%$ ) have substantially higher smoking prevalences $[3,4]$.

Youth ethnicity patterns are comparable to those for adults in New Zealand, although the overall number of young people smoking is considerably smaller than for adults [5,6]. In addition, data from the national youth surveys indicate that these disparities are persisting over time. For example, in 2001 14\% of Pacific youth (ages 13-17 years) and 7\% of their New Zealand European peers were classified as smokers [7]. By 2007, the 
prevalence decreased for both groups to $12 \%$ and 6\% respectively, but the prevalence gap still persists between the two groups [8]. The annual national Year 10 student surveys (students aged 14-15 years), showed that in 1999, 23.0\% of Pacific students were smokers compared to $13.1 \%$ of NZ European students. In 2008, 10.5\% of Pacific students were smokers compared to $4.1 \%$ of NZ European students [5]. These disparities contribute to significant health inequalities between ethnic and socioeconomic groups and more attention is required to address tobacco use amongst key ethnic groups, who may not be experiencing beneficial effects from populationwide tobacco control interventions $[9,10]$.

This study contributes to the call for more comprehensive data on tobacco use amongst Pacific people, who are a key ethnic group currently experiencing health disadvantages [11]. Tobacco research has so far tended to highlight the predictors of tobacco use amongst Pacific adults $[4,12-16]$. To the authors' knowledge, this is the first study examining the predictors of cigarette use amongst Pacific youth in New Zealand.

\section{Methods}

\section{Survey background}

Data for the current study were collected as part of Youth'07, a nationally representative sample of the health and wellbeing of secondary school students in New Zealand. First, 115 schools were randomly selected and 96 agreed to participate in the survey, representing an $84 \%$ response rate for schools. The participating schools reflected the general characteristics of secondary schools in New Zealand [17]. From the participating schools, students $(n=12,355)$ were randomly selected from the school roll and invited to participate. Of these, a total of 9,107 students took part and formed the final Youth'07 sample, representing a $74 \%$ response rate and $3.4 \%$ of the total 2007 New Zealand secondary school roll.

The survey included a 622 item multimedia questionnaire administered on a Nokia internet tablet. On the day of the survey, students were asked to come to a designated room and upon arrival students were given an anonymous login code to access the questionnaire and identification of their census meshblock number (based on their residential address) to determine the extent of their neighbourhood deprivation. The multimedia nature of the questionnaire meant that all students could read each question and response options themselves, while listening to the questions and responses being read aloud through headphones.

The University of Auckland Human Subject Ethics Committee granted ethical approval for the study. Students and their parents were provided with information sheets about the survey. Students consented themselves to participate in the study on the day of the survey. A more detailed description of the research methodology can be obtained elsewhere [17].

Secondary analysis of the data provided by Pacific students (13\% of the total sample) was undertaken. Ethnicity was recorded using New Zealand 2006 Census ethnicity question whereby participants select all of the ethnic groups that they identified with [18]. All students who self-identified any of their ethnic groups as Samoan, Cook Islands, Tongan, Niue, Tokelauan, Fijian, or Other Pacific Peoples were amalgamated to the Pacific grouping, and are included in these analyses $(n=1178)$. New Zealand European students identified through ethnic prioritisation (i.e., students that are non-Maori, non-Pacific, non-Asian) were included in the analyses $(n=4797)$. Intra-Pacific ethnicity analyses could not be completed as findings may be confounded by small sample numbers.

\section{Outcome measures}

To assess smoking prevalence, adolescents were asked the question "Have you ever smoked a whole cigarette?" and if they indicated "Yes", a further branching question was presented; "How often do you smoke cigarettes now?" This frequency question had five response options; (1) never - I don't smoke now; (2) occasionally; (3) once or twice a month; (4) once or twice a week; (5) most days. These five responses were dichotomised into two categories, with adolescents choosing options (2) - (5) classed as current smokers and those choosing option (1) as non-smokers.

\section{Smoking contexts}

To find out where adolescents were obtaining cigarettes, they were asked "When you smoke cigarettes how do you usually get them?" Participants were presented with nine choices, with the ability to choose multiple options. Eight of these were used in this study; (1) I buy them myself; (2) I get them from friends; (3) I get them from brothers and/or sisters; (4) I get them from parent(s); (5) I get them from another adult I know; (6) I get someone else to buy them for me; (7) I pinch them; (8) I get them from a tobacco vending machine. The last response option "none of these" was excluded from the analyses.

Adolescents who purchased cigarettes themselves were asked to indicate where they most often bought their cigarettes, choosing from six options: (1) supermarket; (2) dairy; (3) pub; (4) vending machine; (5) petrol station; (6) other people. As the legal age of tobacco purchasing in New Zealand is eighteen years old, a question on showing age identification (ID) when purchasing cigarettes was included; "When buying cigarettes are you ever asked to show ID?" Four options were available: (1) almost never; (2) hardly ever; (3) sometimes; (4) most of the time. 
A question on age of first smoking occasion was included in the study, as was a question on whether adolescents had ever tried to cut down or give up smoking cigarettes.

\section{Home \& social environments factors}

Adolescents were asked whether their parent(s) at home used cigarettes, tobacco, and this question was repeated for friends. Home environment items used in analyses were about whether parents had knowledge of the adolescents' friends, whereabouts after school, and whereabouts at night time.

\section{Alcohol binge drinking factors}

Binge drinking was measured by a series of branching questions. First, adolescents were asked "Have you ever drunk alcohol (not counting a few sips?)" If they responded yes, they were asked "In the past 4 weeks, how many times did you have 5 or more alcoholic drinks in one session within 4 hours?" with response categories "none at all', "once in the past 4 weeks", "two or three times in the past 4 weeks", "every week", or "several times a week". Those who reported drinking 5 or more alcohol drinks in one session at least once in the last 4 weeks were classed as binge drinkers $(n=305)$. A question on age of first alcohol drinking occasion was included in the study.

\section{Demography}

Age, gender and ethnicity were determined by self-report. Small area deprivation (NZDep) was determined using the 2006 New Zealand Deprivation Index [19]. For descriptive purposes, the NZDep Index deciles were categorized into three groups reflecting low deprivation (1-3), middle levels of deprivation (4-7), and high deprivation $(8-10)$.

\section{Analysis}

Frequencies and percentages were used to describe the characteristics of students. Chi-square tests were used to investigate the bivariate associations between ethnicity and outcome variables. Adjusted odds ratio (OR) was estimated using logistic regression models controlling for age, sex and socio-economic deprivation. All analyses were conducted using the procedures in the SAS software v9.2 (Cary, NC) and accounted for the clustered design of the data.

\section{Results}

Table 1 shows that Pacific youth were smoking at twice the prevalence rate $(11.9 \%)$ of NZ European young people $(5.6 \%)$ and that this difference is significant $(\mathrm{p}<0.001)$. Pacific adolescent girls were smoking at almost twice the rate $(15.4 \%)$ of Pacific adolescent boys $(8.5 \%, \mathrm{p}=0.001)$. Older Pacific youth aged 16-17 years smoked cigarette more than younger adolescents' aged 13-14 years $(\mathrm{p}=$ 0.02). Pacific youth from higher and mid-deprivation neighbourhoods smoked at twice the rate of youth from low deprivation areas, although possibly due to small numbers of Pacific youth from low deprivation neighbourhoods this was not statistically significant $(\mathrm{p}=0.29)$.

\section{Smokers source of cigarettes}

Most Pacific adolescents (77.4\%) indicated that they received their cigarettes from their friends. The legal age

Table 1 Cigarette use by key demographic variables amongst Pacific and NZ European adolescents

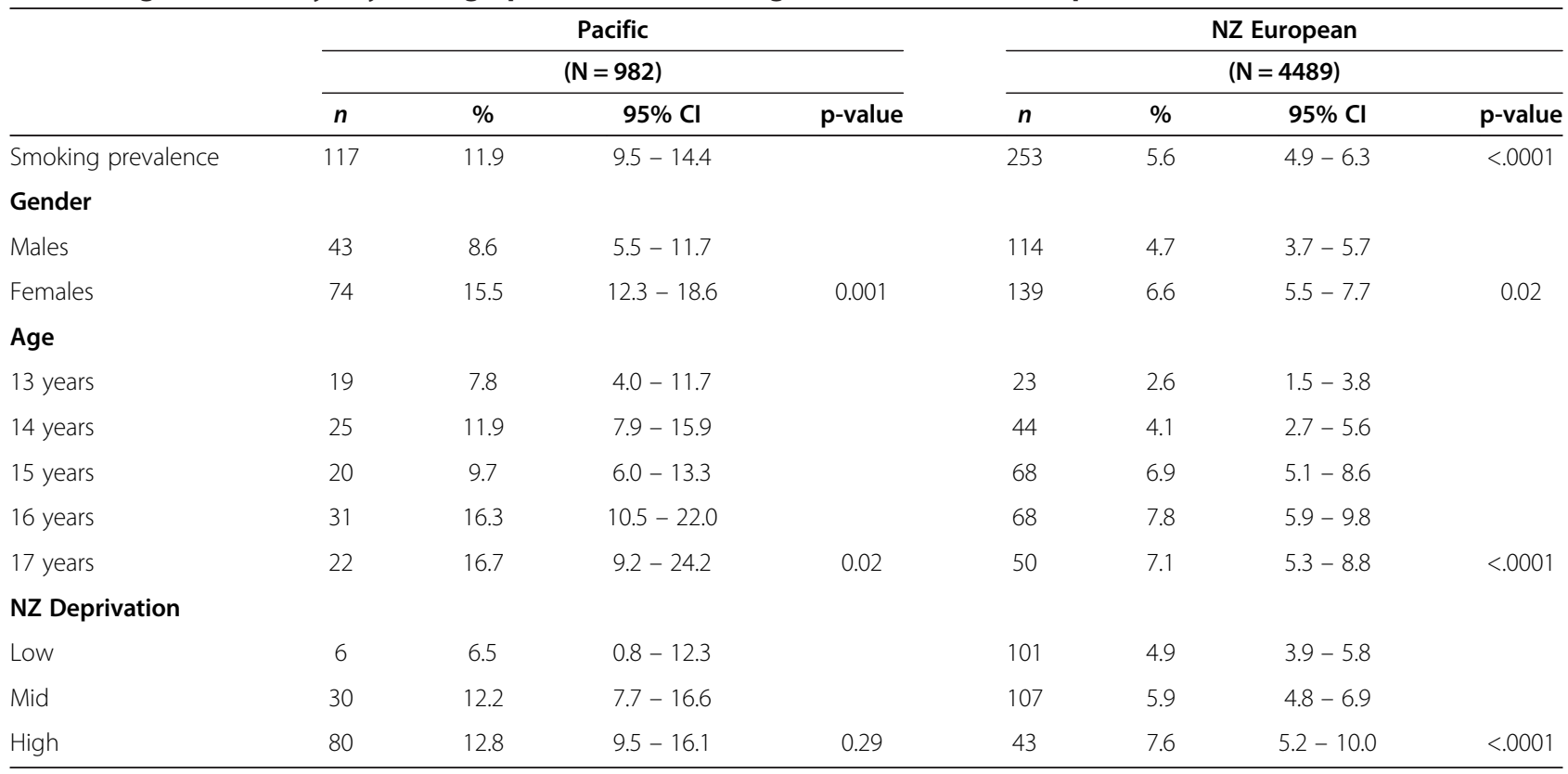


for purchasing cigarettes in New Zealand is eighteen years old, yet almost half (40.8\%) of the adolescents in this study said they purchased cigarettes themselves. About one in three chose options of other people buying cigarettes for them; I get someone else to buy them for me - 33.8\%; I get them from brothers and/or sisters 30.5\%; I get them from another adult I know - 28.7\%. One in four adolescents $(24.4 \%)$ disclosed that they stole cigarettes for use (I pinch them) and16.2\% of Pacific adolescents indicated that they got cigarettes from their parent. Relatively few students, $6.1 \%$ used a tobacco vending machine to get cigarettes.

\section{Locations for purchasing cigarettes}

Adolescents who purchased cigarettes themselves were asked to indicate where they most often bought their cigarettes, choosing from six options. Table 2 shows that local neighbourhood dairies (stores) were the most frequent locations for adolescents purchasing cigarettes (55.1\%). Almost one in four (23.1\%) adolescents would buy cigarettes from other people, and $12.6 \%$ chose petrol stations, as their most often used place for purchasing tobacco. As tobacco purchase in New Zealand is legally restricted for under-eighteen year olds, adolescents were asked when buying cigarettes, if they were asked identification (ID) to confirm their age. Only one in eight (12.7\%) adolescents revealed they were asked for age identification most of the time and the majority of students (87.3\%) were sometimes; hardly ever; and almost never asked for ID at the time of purchasing cigarettes.

Table 3 shows results of the analysis undertaken to test whether Pacific adolescent smoking is associated with parental and peer cigarette use, parental monitoring and alcohol binge drinking behaviours. The analyses revealed that Pacific adolescents were smokers if their parents were smokers and if their friends were smokers. The

Table 2 Sources and locations of cigarette purchasing amongst Pacific adolescents

\begin{tabular}{lccc}
\hline Place adolescents most often buy cigarettes & $\boldsymbol{n}$ & $\%$ & $\mathbf{9 5 \%} \mathbf{C l}$ \\
\hline Dairy & 48 & 55.1 & $45.0-65.2$ \\
Other people & 20 & 23.1 & $14.0-32.1$ \\
Petrol Station & 11 & 12.6 & $6.0-19.2$ \\
Supermarket & 6 & 6.9 & $1.3-12.4$ \\
Pub & 2 & 2.3 & $0.0-5.7$ \\
Vending machine & 0 & 0.0 & - \\
When buying cigarettes are you & $n$ & $\%$ & \\
ever asked to show ID? & & & \\
Almost never & 39 & 44.8 & $35.0-54.5$ \\
Hardly ever & 17 & 19.6 & $10.3-28.8$ \\
Sometimes & 20 & 22.9 & $14.1-31.7$ \\
Most of the time & 11 & 12.7 & $6.6-18.7$ \\
\hline
\end{tabular}

odds ratio revealed that Pacific adolescents were almost 3 times more likely to smoke cigarettes if they had a parent who was also a smoker $(\mathrm{OR}=2.6 ; 95 \%$ CI1.8 - 3.8) and almost all Pacific adolescent smokers indicated that their friends were also smokers, highlighting a strong association amongst social peers and smoking behaviours.

In terms of parental monitoring, there was a significant association between smoking and low parental monitoring, that is, parents not knowing the whereabouts of their youth during after school hours or at night times and who their adolescents' friends were, had an increased likelihood for adolescent smoking.

There was a significant association between alcohol binge drinking and smoking, with almost three-quarters of smokers $(71.1 \%)$ revealing that they also engaged in binge drinking alcohol. Adolescents were asked to identify how old they were when they first smoked a whole cigarette, and how old they were when they first drank alcohol. The mean age was calculated to assess which substance use behaviour came first. The mean age for the first smoking occasion was 12.1 years (standard error of mean 0.16 , 95\% CI for mean 11.79 - 12.41). The mean age for the first alcohol drinking occasion was 12.9 years (standard error of mean $0.11,95 \%$ CI for mean 12.70 - 13.16).

All adolescents who had tried cigarettes once were asked if they had ever tried to cut down or give up smoking cigarettes? The majority of students (70.2\%) indicated that they had tried to decrease or quit smoking.

\section{Discussion}

This study provides some contexts around cigarette use amongst Pacific youth in New Zealand. We have found that Pacific youth smoke at twice the rate of their New Zealand European counterparts, and higher rates of smoking amongst female Pacific youth and older Pacific youth.

Pacific youth patterns of smoking are unique in gender use, with Pacific girls being much more likely to be smokers than are boys, yet current statistics for adult smokers, indicate that Pacific men use tobacco more than Pacific women [19]. It is not well understood what may be contributing to the differences in gender-related use. Some data suggest that New Zealand born Pacific girls and women are much more likely to be smokers than are Pacific migrant girls and women $[13,14,20]$. If this is true, it is likely that future prevalences for Pacific women would increase to match men, as the Pacific populations have become increasingly New Zealand born.

The results of the study also reveal that illegal, underaged cigarette purchasing appears to occur with regularity in amongst Pacific young people in New Zealand. Dairies (small local neighbourhood stores) were the most frequented location for purchasing cigarettes illegally and most youth cigarette purchasing did not require age 
Table 3 Prevalence and adjusted odds of Pacific adolescent cigarette smoking by selected home, social and alcohol use variables

\begin{tabular}{|c|c|c|c|c|c|c|c|}
\hline & \multicolumn{2}{|c|}{$\begin{array}{l}\text { Cigarette smoking } \\
\quad(\mathrm{N}=117)\end{array}$} & \multicolumn{2}{|c|}{$\begin{array}{c}\text { Not cigarette } \\
\text { smoking }(\mathrm{N}=856)\end{array}$} & \multirow[b]{2}{*}{ Odds ratio* } & \multirow[b]{2}{*}{$95 \% \mathrm{Cl}$} & \multirow[b]{2}{*}{ p-value* } \\
\hline & $n$ & $\%$ & $n$ & $\%$ & & & \\
\hline Parents smoke & 77 & 65.7 & 361 & 42.2 & 2.6 & $1.8-3.8$ & $<0.001$ \\
\hline Friends smoke & 112 & 95.7 & 525 & 61.4 & 10.6 & $4.4-26.2$ & $<0.001$ \\
\hline Parents have knowledge of where student goes to after school & 82 & 74.5 & 772 & 92.3 & 0.25 & $0.12-0.48$ & $<0.001$ \\
\hline Parents have knowledge of where student goes at night time & 71 & 65.7 & 681 & 85.1 & 0.31 & $0.18-0.56$ & $<0.001$ \\
\hline Parents have knowledge of who students' friends are & 91 & 80.5 & 742 & 87.1 & 0.5 & $0.28-0.89$ & 0.02 \\
\hline Binge-drink & 78 & 71.1 & 219 & 26.5 & 6.5 & $3.8-11.0$ & $<0.001$ \\
\hline
\end{tabular}

*adjusted for age, gender and deprivation.

identification to comply with current laws. This highlights a significant flouting of the law by retailers and a lack of law enforcement. This study supports the strategies to limiting youth access by increasing penalties for vendors who sell under-age cigarettes and to increase the individual purchase price for cigarettes [21]. Increasing the cost of cigarettes has been found to be effective for Pacific young people's attempts to stop smoking [16].

This study confirmed the salience of parental and peer-use on adolescent smoking behaviours, which affirms previous research on social influences [22-26]. Parental monitoring, that is, having parents who knew the whereabouts of their young people during after-school hours and at night time, decreased the likelihood of youth smoking behaviours. This finding confirms previous research on the role of parental monitoring in decreasing adolescent smoking risk [27-30]. Having a friend who was a smoker was much more likely to influence Pacific youth smoking behaviours and friends who were also smokers were significant suppliers of cigarettes. The significant role of peers with respect to $\mathrm{Pa}$ cific youth smoking is common amongst adolescents in general and this is likely to be a combination of peer pressure, and 'peer selection', where young people choose to be with similar others [30-32].

In addition, alcohol use was also a regular feature for $\mathrm{Pa}-$ cific youth smokers. The co-occurrence of both cigarette and alcohol use is emerging from recent literature [33-35] and its existence for Pacific groups is supported by some data on adults [36]. This study revealed that both substance initiations occurred in the pre-teen years for Pacific young people. The co-occurrence of the use of both substances highlights the need for both prevention and management strategies to be targeted at younger age-groups, and for youth quit-smoke or quit-drink programmes to be offered in tandem with one another. Our study found most Pacific youth smokers had tried to quit smoking, but emerging data highlight a lack of accessibility to quitsubstance-use programmes [37]. Pacific participants in a qualitative study indicated a lack of awareness and use of mainstream quit-smoking services and products and that most Pacific people stopped unaided, that is, going "cold turkey" [16]. Youth in particular, had very limited health service knowledge and may be unsupported in their attempts to quit an addictive substance [16].

The strengths of this study include the use of nationally representative data and ability to present Pacific youth health data exclusively. In most cases, ethnic research data is presented in amongst national data sets and publications which make it difficult for researchers to access ethnic-specific information. As health patterns across most OECD countries follow distinct trends, particularly entrenched health disparities across ethnic groups [38-41], it becomes more important to publish health information for each disadvantaged group that may require quite specific and unique resolutions.

A limitation of this study is that it could not complete intra-Pacific analyses due to small sample numbers. Previous research does indicate that different Pacific island groups, like the eastern Polynesian groups of CookIslanders and Niueans have much higher smoking rates compared to the western Polynesian groups of Samoans and Tongans [5,42]. However, taken individually, each Island group has substantially higher smoking rates compared to their New Zealand European counterparts and further breakdown by intra-Pacific groups would not add further value to conclusions for addressing youth smoking behaviours proposed here.

\section{Conclusion}

The persistence of unequal rates of cigarette use over time between ethnic groups is concerning and one that calls for both public-health policy approaches and for unique Pacific community-focused approaches. A strategy for addressing ethically the issue of equal health for all is to allocate increased public health investments in targeted quit-smoking treatment programmes for Pacific youth in New Zealand. Further qualitative studies with Pacific youth to inform the development of culturally-appropriate youth-focused quitsubstance interventions is recommended. 


\section{Competing interests}

The authors declare that they have no competing interests.

\section{Authors' contributions}

All authors were involved in the study design. $\Pi$ led the writing of the manuscript which was reviewed by all authors who approved the final version of the manuscript. SD led the statistical analysis for the study. All authors read and approved the final manuscript.

\section{Acknowledgements}

Thanks to students, staff and schools who participated in Youth'07. The Youth'07 study was funded by the Health Research Council of New Zealand (grant 05/216), Department of Labour, Families Commission, Accident Compensation Corporation, Sport and Recreation New Zealand, Alcohol Advisory Council of New Zealand and Ministries of Youth Development, Justice and Health.

\section{Author details}

${ }^{1}$ School of Population Health, University of Auckland, Auckland, New Zealand. ${ }^{2}$ Department of Community Paediatrics, School of Population Health, University of Auckland, Auckland, New Zealand. ${ }^{3}$ Pacific Health, School of Population Health, University of Auckland, Private bag 92019, Auckland 1142, New Zealand. ${ }^{4}$ School of Pharmacy, University of Auckland, Auckland, New Zealand.

Received: 21 January 2013 Accepted: 28 September 2013

Published: 17 October 2013

\section{References}

1. WHO World Health Organization: WHO global report: mortality attributable to tobacco. Geneva: WHO; 2012

2. Ministry of Health: The health of New Zealand adults 2011/12: Key findings of the New Zealand health survey. Wellington, New Zealand: Ministry of Health; 2012.

3. Ministry of Health: Tobacco trends 2008: a brief update of tobacco use in New zealand. Wellington, New Zealand: Ministry of Health; 2009.

4. Ministry of Health: Tupu Ola moui: pacific health chart book 2012. Wellington, New Zealand: Ministry of Health; 2012.

5. Paynter J: National year 10 ASH snapshot survey, 1999-2009: trends in tobacco use by students aged 14-15 years, Report for ministry of health, health sponsorship council, and action on smoking and health. Auckland, New Zealand: ASH; 2010.

6. ASH New Zealand: Youth smoking in New Zealand by ethnicity. Auckland, New Zealand: ASH; 2013.

7. Mila-Schaaf K, Robinson E, Schaaf D, Denny S, Watson PD: A health profile of pacific youth: findings of Youth2000. A national secondary school youth health survey. Auckland, New Zealand: University of Auckland; 2008.

8. Helu SL, Robinson E, Grant S, Herd R, Denny S: Youth '07 the health and wellbeing of secondary school students in New zealand: results for pacific young people. Auckland, New Zealand: University of Auckland; 2009.

9. Hill SE, Blakely TA, Fawcett JM, Howden-Chapman P: Could mainstream anti-smoking programs increase inequalities in tobacco use? New Zealand data from 1981-96. Aust N Z J Public Health 2005, 29(3):279-284.

10. Wilson N, Blakely T, Tobias M: What potential has tobacco control for reducing health inequalities? The New Zealand situation. Int J Equity Health 2006, 5:14.

11. Rasanathan K, Tukuitonga CF: Tobacco smoking prevalence in Pacific Island countries and territories: a review. N Z Med J 2007, 120(1263):U2742.

12. Carter S, Percival T, Paterson J, William M: Maternal smoking: risks related to maternal asthma and reduced birth weight in a Pacific Island birth cohort in New Zealand. N Z Med J 2006, 119(1238):U2081.

13. Butler S, Williams M, Paterson J, Tukuitonga C: Smoking among mothers of a Pacific Island birth cohort in New Zealand. N Z Med J 2004, 117(1206):U1171

14. Tautolo E-S: Prevalence and concordance of smoking among mothers and fathers within the Pacific Islands Families Study. Pac Health Dialog 2011, 17(2):136.

15. Erick-Peleti S, Paterson J, Williams M: Pacific islands families study: maternal factors associated with cigarette smoking amongst a cohort of pacific mothers with infants. N Z Med J 2007, 120(1256):U2588.
16. Nosa V, Watson D, Stephen J, Tutini R: Pacific data. In WhyKwit: A qualitative study of what motivates Maori, Pacific Island and low socio-economic peoples in Aotearoa/New Zealand to stop smoking. Edited by Glover M, Nosa V, Watson D, Paynter J. Auckland, New Zealand: Centre for Tobacco Control Research, University of Auckland; 2010:89-127.

17. Adolescent Health Research Group: Youth'07: the health and wellbeing of secondary school students in New zealand. Technical report. Auckland: University of Auckland; 2008.

18. Statistics New Zealand: Statistical standard for ethnicity. Retrieved 1 august 2011; 2005. http://www.stats.govt.nz/browse_for_stats/population/ census_counts/review-measurement-of-ethnicity.aspx.

19. Salmond C, Crampton P, King P, Waldegrave C: NZDep: a New zealand index of socioeconomic deprivation for individuals. Soc Sci Med 2006, 62(6):1474-1485.

20. Tautolo E-S, Schluter PJ, Paterson J, McRobbie H: Acculturation status has a modest effect on smoking prevalence among a cohort of Pacific fathers in New Zealand. Aust N Z J Public Health 2011, 35(6):509-516.

21. Wong G, Glover MP, Nosa V, Paynter J, Freeman B, Scragg R: Young people, money and access to tobacco. N Z Med J 2007, 120(1267):2864.

22. Scragg R, Reeder Al, Wong G, Glover M, Nosa V: Attachment to parents, parental tobacco smoking and smoking among Year 10 students in the 2005 New Zealand national survey. Aust N Z J Public Health 2008, 32:348-353.

23. Scragg R, Laugesen M, Robinson E: Parental smoking and related behaviours influence adolescent tobacco smoking: results from the 2001 New Zealand national survey of 4th form students. N Z Med J 2003, 116(1187):U707.

24. Bauman KE, Foshee VA, Linzer MA, Koch GG: Effect of parental smoking classification on the association between parental and adolescent smoking. Addict Behav 1990, 15(5):413-422.

25. French SA, Perry CL: Smoking among adolescent girls: prevalence and etiology. J Am Med Womens Assoc 1996, 51(1-2):25-28.

26. Alexander C, Piazza M, Mekos D, Valente T: Peers, schools, and adolescent cigarette smoking. J Adolesc Health 2001, 29(1):22-30.

27. Clark H, Shamblen S, Ringwalt C, Hanley S: Predicting high risk Adolescents' substance Use over time: the role of parental monitoring. J Prim Prev 2012, 33(2-3):67-77.

28. Piko BF, Balazs MA: Authoritative parenting style and adolescent smoking and drinking. Addict Behav 2012, 37(3):353-356.

29. Li X, Stanton B, Feigelman S: Impact of perceived parental monitoring on adolescent risk behavior over 4 years. J Adolesc Health 2000, 27(1):49-56.

30. Simons-Morton B, Haynie DL, Crump AD, Eitel P, Saylor KE: Peer and parent influences on smoking and drinking among early adolescents. Health Educ Behav 2001, 28(1):95-107.

31. Steinberg L, Fletcher A, Darling N: Parental monitoring and peer influences on adolescent substance Use. Pediatr 1994, 93(6):1060-1064.

32. Hoffman BR, Monge PR, Chou C-P, Valente TW: Perceived peer influence and peer selection on adolescent smoking. Addict Behav 2007, 32(8):1546-1554.

33. Myers MG, Kelly JF: Cigarette smoking among adolescents with alcohol and other drug Use problems. Alcohol Res Health 2006, 29(3):221-227.

34. Johnson PB, Boles SM, Vaughan R, Kleber HD: The co-occurrence of smoking and binge drinking in adolescence. Addict Behav 2000, 25(5):779-783.

35. Wilson N, Weerasekera D, Kahler CW, Borland R, Edwards R: Hazardous patterns of alcohol use are relatively common in smokers: ITC Project (New Zealand). N Z Med J 2012, 125(1348):U5022.

36. Hale M, McCool J, Nosa V, Bullen C: Views from a small Pacific island: prospects for tobacco control on Niue. Health Promot Pract 2012, 13(3):404-411.

37. Teevale T, Denny S, Percival T, Fleming T: Pacific secondary school students' access to primary health care. N Z Med J 2013, 126(1375):58-68.

38. Keppel KG: Ten largest racial and ethnic health disparities in the united states based on healthy people 2010 objectives. Am J Epidemiol 2007, 166(1):97-103.

39. Nazroo JY: The health of Britain's ethnic minorities: findings from a national survey. London, England: Policy Studies Institute; 1997.

40. Nazroo JY: The structuring of ethnic inequalities in health: economic position, racial discrimination, and racism. Am J Public Health 2003, 93(2):277-284 
41. Ajwani S, Blakely T, Robson B, Tobias M, Bonne M: Decades of disparity: ethnic mortality trends in New zealand 1980-1999. Wellington, New Zealand: Ministry of Health and the University of Otago; 2003.

42. Novak B: Ethnic-specific health needs assessment for pacific people in counties manukau. Manukau City, New Zealand: Counties Manukau District Health Board; 2007.

doi:10.1186/1477-7517-10-25

Cite this article as: Teevale et al:: Predictors of cigarette use amongst Pacific youth in New Zealand. Harm Reduction Journal 2013 10:25.

\section{Submit your next manuscript to BioMed Central and take full advantage of:}

- Convenient online submission

- Thorough peer review

- No space constraints or color figure charges

- Immediate publication on acceptance

- Inclusion in PubMed, CAS, Scopus and Google Scholar

- Research which is freely available for redistribution 